\title{
The IMIA History Working Group: Inception through the IMIA History Taskforce, and Major Events Leading Up to the 50th Anniversary of IMIA
}

\author{
C. A. Kulikowski', G. Mihalas ${ }^{2}$, R. A. Greenes ${ }^{3}$, V. Yacubsohn' ${ }^{4}$ H.-A. Park \\ 1 Rutgers - The State University of New Jersey, Piscataway, New Jersey, USA \\ 2 Victor Babes University of Medicine \& Pharmacy, Timisoara, Romania \\ 3 Department of Biomedical Informatics, Arizona State University, Tempe, Arizona, USA \\ 4 School of Public Health, Faculty of Medicine, University of Buenos Aires, Buenos Aires, Argentina \\ 5 College of Nursing, Seoul National University, Seoul, Korea
}

up to the current work of the IMIA History WG and how it has stimulated writing on the international history of biomedical and health informatics, sponsoring the systematic compilation and writing of articles and stories from pioneers and leaders in the field, and the organization of workshops and panels over the past six years, leading towards the publication of the contributed volume on the 50th IMIA Anniversary History as an eBook by lOS Press.

Conclusions: This article leads up to the IMIA History eBook which will contain original autobiographical retrospectives by pioneers and leaders in the field, together with professional organizational histories of the national and regional societies and working groups of IMIA, with commentary on the main themes and topics which have evolved as scientific and clinical practices have changed under the influence of new insights, technologies, and the changing socio-economic, cultural and professional circumstances around the globe over the past 50 years.

\section{Keywords}

IMIA, History of International Biomedical and Health Informatics, History Working Group, IMIA 50th Anniversary

Yearb Med Inform 2017:263-8

http://dx.doi.org/10.15265/IY-2017-002

Published online May 8, 2017 projects, leading to the forthcoming 50th Anniversary of IMIA.

Methods: We give a chronology of major developments leading

\section{Overview}

The IMIA History working group (WG) developed from the activities of the IMIA History Taskforce, which was formed as result of the encouragement of the IMIA Board and General Assembly meeting during the Asia Pacific Association for Medical Informatics (APAMI) Conference held in Hiroshima in 2009. This, in turn, built on preliminary discussions that had begun a few years earlier among members of the IMIA Board, on how to document the development and evolution of the field in its international dimensions, focusing on the role of IMIA and its constituent societies in writing, from international perspectives, on the contrasting advances and persistent challenges faced by the field in terms of its research, practice, and education.

\section{Formation of the IMIA History Taskforce}

During the APAMI 2009 meeting held in Hiroshima, the IMIA Board and General Assembly (GA) heard a proposal presented by then Vice President (VP) for Services, Professor Casimir Kulikowski. He recom- mended that a Taskforce be formed related to the History of Biomedical and Health Informatics. He argued that such a step would be desirable to document and archive the materials generated by IMIA during the course of its history. Diarmuid Ua Connail, IMIA's then Secretary, indicated that he had many files on the minutes of the IMIA Board and GA. An informal Taskforce was organized and agreed that these records, if kept in a repository online, could allow tracking of developments of groups and initiatives within IMIA as well as changes in leadership and future directions. In addition, the Taskforce was charged to coordinate and channel the interests of those IMIA members 
interested in the history of the organization as well as urge the recording of personal and group recollections and writings about developments in informatics from a wide range of international viewpoints.

The first members leading the ad hoc IMIA History Taskforce, hereafter referred to simply as the History Taskforce, included representatives from all the major regional associations: Casimir Kulikowski (USA/AMIA-North America), George Mihalas (Romania/EFMI-Europe), Hyeoun-Ae Park (Korea/APAMI - Asia-Pacific), Sedick Isaacs (South Africa/HELINA - Africa), and Alvaro Margolis (Uruguay/ IMIA-LAC - Latin America). The IMIA History Taskforce sponsored the gathering of IMIA-related archival materials and developed a prototype media repository at Rutgers University (http://infohistory.rutgers.com). The materials repository helped in writing and chronicling the development and evolution of IMIA, its contributors, its sponsored events and publications, its history $[1,2,3,4,5,6,7,8,9,10,11]$, as well as educational $[12,13,14]$ and other professional activities. In particular, Diarmuid Ua Connail collected materials from previous IMIA meetings and provided them to the Rutgers MediaWiki archive.

Initiatives related to the IMIA History Taskforce from 2009 to 2014 included workshops and panels at a large number of international and regional conferences, including: Medinfo 2010 held in Cape Town, IMIA-LAC in Guadalajara in 2011, as well as most AMIA Annual Meetings and ACMI Meetings since 2011, MIE 2011 in Oslo, APAMI in Beijing in 2012, a workshop in Prague in conjunction with the EFMI-STC in 2013, the Medinfo 2013 Congress held in Copenhagen, MIE 2014 in Istanbul, APAMI 2014 in New Dehli, Medinfo 2015 in Sao Paulo, EFMI-STC 2016 in Paris, NI 2016 in Geneva, HECEFMI 2016 in Munich, and the ACMI meetings celebrating the 40th Anniversary of SCAMC at AMIA-2016 in Chicago. The IMIA History WG formally received IMIA Board approval at the New Delhi meeting (2014). A summary of past and future major developments carried out under the auspices of the IMIA History Working Group follows.

\section{History Workshop at Medinfo 2010 in Capetown, South Africa: Introduction of the ad hoc IMIA History Taskforce}

The discussions at the Medinfo 2010 History Workshop in Capetown demonstrated enthusiasm of the participants for the History Taskforce projects and received many commitments for writing on personal and specialty topics by a wide range of IMIA members. Lyn Hanmer, Secretary of IMIA at the time, and leader of SAHIA and HELINA, organized the conference. Casimir Kulikowski, serving as VP for Services, gave a report about the ad hoc History Taskforce which had been constituted after the Hiroshima IMIA meeting, and outlined its objectives of developing a plan for writing a History of International Medical Informatics (MI) to be published by IMIA in conjunction with the 50th Anniversary of the Association in 2017; surveying the literature on the history of MI and developing an index of resources, and database of sources/resources to support the creation of the initial outline of the History, through a MediaWiki at Rutgers University; developing a funding plan for IMIA to support these activities.

Following this meeting, pioneers in medical informatics were contacted, and their support obtained for the proposed work. The National Library of Medicine in the US also provided positive feedback, as did the IEEE History Center. The workshop at Medinfo 2010 discussed a number of alternative histories of medical informatics - beyond the mainstream, and a meeting for INFOLAC was planned. Charles McGrew of the Rutgers Laboratory for Computer Science Research assisted in the development of the prototype MediWiki to include short biographies, meeting and publication descriptions, salient dates and a timeline of IMIA, and helped in preparing an outline of the 50th Anniversary IMA History book to be released in 2017.

\section{History Workshop at IMIA-LAC 2011 in Guadalajara, Mexico}

A large number of Latin American experts in Biomedical and Health Informatics as well as many others from around the world participated to this workshop [15]. Valerio Yacubsohn of Argentina, a pioneer in the organization, described in depth how IMIALAC had evolved. Together with Alvaro Margolis of Uruguay, they committed to create a written version of the IMIA-LAC history as well as recruit volunteers from the region. They enjoyed the active support of Dr. Amado Espinosa of Mexico, the Chair and host of the IMIA-LAC 2011 Conference.

\section{Formation of the ACMI Committee of Historians in the US at AMIA 2011 in Washington, $D C$}

The American College of Medical Informatics (ACMI) includes international members and as such, it is a leading professional organization for distinguished researchers and practitioners in biomedical and health informatics worldwide. Upon hearing of the IMIA History Taskforce activities, it constituted an ACMI Committee of Historians, at the AMIA 2011 meeting. The Committee defined goals and a scope of work including history-oriented activities for the $30^{\text {th }}$ anniversary of the 1984 formation of ACMI in 2014. Specific activities included a description by Professors Joan Ash and Dean Sittig of the National Library of Medicine (NLM) Oral History Project which they lead as well as possible future connections to other projects at the NLM as well as with IMIA.

\section{Methods of Information in Medicine Jubilee Conference, Heidelberg, June 11, 2011}

Reinhold Haux, long-time editor of Methods, organized the Jubilee meeting to celebrate the $50^{\text {th }}$ Anniversary of the first journal in medical informatics that was founded by Gustav Wagner in 1962 in Heidelberg. Contributions of Methods to the history of 
the field were discussed, including the role of Schattauer Publishers, which later also produced the IMIA Yearbook of Medical Informatics since it was founded by Jan van Bemmel and Alexa McCray in 1992. There was considerable discussion about the different threads of research, education, and practice in medical informatics and the evolution of the field internationally. The roles of citation analysis and the need to supplement this approach in producing a more complete historical record of the evolution of biomedical and health informatics was also a topic. The difficulties faced by journals, authors, and publishers with the system of impact factors and how this affects publication and can constrain the dissemination of novel ideas and methods was seen as influencing how a highly heterogeneous field like biomedical and health informatics evolves. The meeting was especially valuable in bringing together the many senior contributors to the field who had served Methods and the IMIA Yearbook in an editorial capacity, providing strong leadership in emphasizing the scientific research of informatics.

\section{IMIA History Taskforce at APAMI 2012 in Beijing, China}

At the History Taskforce meeting during APAMI 2012 in Beijing, progress was reported on the development of the wiki (http://infohistory.rutgers.edu) [16] produced at Rutgers. The wiki contains timelines, member and event profiles plus bio-sketches for IMIA and ACMI members including links to publications and IMIA documents. Diarmuid UaConnaill had retrieved, scanned, and provided digital copies of IMIA archival Board, GA, and other documents. A photographic archive of IMIA events was assembled and linked to the timeline. An experiment in text analysis of IMIA documents found frequencies of references to IMIA officers and patterns of events and social. The IMIA Board reiterated its support for the work of the Taskforce, indicating that it would look favorably at funding publication of a book to celebrate the history of IMIA on its $50^{\text {th }}$ anniversary in 2017. At this meeting Reinhold Haux quoted Thomas More on the importance of history: "Tradition is not to preserve the ashes, it is passing on the fire."

\section{History Workshop at EFMI- STC 2013 in Prague, Czech Republic}

A major step forward in the IMIA history activities happened at a special EFMI History Workshop organized by George Mihalas, Jana Zvarova, and Casimir Kulikowski. The workshop was sponsored by the History Taskforce, with strong participation of many of its members [17]. Panelists were Marion Ball, Jan H van Bemmel, Arie Hasman, Izet Masic, and Diane Whitehouse. In addition, written comments from Barry Barber and Maureen Scholes were read in their absence. The Workshop was associated with the PragueSTC EFMI Meeting in April 2013. Jan H van Bemmel discussed the evolution of people and ideas in Medical Informatics, pointing out how nobody predicted personal computers in the 1970s, the world-wide web in 1991, the rapid rise of the Internet and world wide web, and the spread of social media in this century. Hence, nobody expected that human factors, rather than hardware or software, would become crucial for the successful applications of computers in health care. Whitehouse reviewed challenges of active and healthy ageing, Europe's eHealth action plan for 2020, and Digital Futures 2050, envisioning healthy lifestyles supported by information and communication technologies. Arie Hasman gave an abridged history of medical informatics education, the Netherlands experiences, the first international IMIA Recommendations on Education in 2000, and work on IMIA Program Accreditation. Jana Zvarova reviewed the history of medical informatics in the Czech Republic, its relationship to statistics and epidemiology, and the series of IMIA and EFMI Meetings held in Prague from 1985 to the 2013 EFMI-STC. Marion Ball spoke on what history can teach us in medical informatics, while George Mihalas focused on the evolution of concepts in the field. Izet Masic spoke on staging developments across the decades while Casimir Kulikowski gave an update on the $50^{\text {th }}$ Anniversary IMIA History Project. Barber and Scholes' comments were about the early developments in health informatics in the UK. Some of the papers were subsequently published in Acta Informatica [18, 19, $20,21]$ and later, partly re-published in an edited volume Contributions to the History of Medical Informatics edited by Masic and Mihalas [22].

\section{History Workshop at Medinfo 2013 in Copenhagen, Denmark}

The workshop broadened the involvement of the IMIA community in the process of planning and implementing the $50^{\text {th }}$ Anniversary History of IMIA as an edited volume, and as materials available online on the IMIA MediaWiki. The Taskforce showed selections from the IMIA-related archival materials, accessible through the prototype MediaWiki at Rutgers University to help those contributing to the book or writing their own recollections and histories. The materials support a chronicle of the development and evolution of IMIA, its contributors, its sponsored events and publications, educational and other professional activities. The Workshop included recollections about the 1966 Elsinore meeting that was the first broad-ranging international meeting that set the stage for the founding of IFIP-TC4, which evolved into IMIA. The Taskforce received feedback on the application of novel informatics methods from text mining, graphical display and visualization to the materials that the IMIA community was gathering as part of the plans for producing the $50^{\text {th }}$ Anniversary IMIA History volume and website. 


\section{Approval of the IMIA History Working Group at the IMIA GA during APAMI 2014 in New Delhi, India}

During 2014, Casimir Kulikowski and George Mihalas drafted a proposal for the transformation of the History Taskforce into a formally recognized IMIA Working Group with official standing in order to help sponsor and coordinate historical writing on biomedical and health informatics from an international perspective. The proposal, submitted to the IMIA Board and GA in the late summer of 2014, included objectives and plans for action. The IMIA Biomedical and Health Informatics History Working Group which will continue to be known in the future as the IMIA History Working Group, was approved at the IMIA GA held in New Delhi in conjunction with APAMI 2014 in August of that year. The approved objectives for the History WG are consistent with its past work, e.g. to sponsor meetings, investigations, studies, and to generate materials and publications on the history of biomedical and health informatics. However, the History WG extended the activities of the History Task Force, providing coordinating mechanisms for activities of different regional and national groups engaged in related historical studies of the field. The current work plan for the History WG focuses on gathering, archiving, and indexing historical documents and materials from IMIA and related professional societies, institutional and individual sources, developing and maintaining a web-site and a MediaWiki for these purposes, and sponsoring the publication of an eBook on the History of International Biomedical and Health Informatics that summarizes and disseminates the results. Dr. Gogia, who chaired the APAMI meeting, organized a session on the history of medical informatics in the Asia-Pacific Region and brought together the contributors for the IMIA History project from this region.

\section{EFMI History Workshop at MIE 2014 in Istanbul, Turkey}

Mihalas organized a Workshop at MIE 2016, where he and van Bemmel, Richards,
Engelbrecht, Masic, Haux, and Kulikowski discussed "Medical Informatics History - A View from Socio-Political Context in European Countries" [23], contrasting the differing experiences of participants during the days when eastern and western Europe had completely different socio-political and economic systems, which strongly impacted the medical, scientific, and technological developments in health informatics.

\section{ACMI History Panels at AMIA 2014 in Washington, DC, USA}

After the official formation of the IMIA History WG, its members participated in the organization and chairing of the ACMI History Sessions (Kulikowski and McCray) during AMIA 2014 in Washington, DC. Two panels identified themes and topics in the history of biomedical and health informatics, and traced how they have developed and evolved over the history of the field. The first panel discussed the founding of ACMI and how AMIA arose from ACMI merging with SCAMC and AAMSI, and included Donald A.B. Lindberg, Thomas Piemme, Ted Shortliffe, Marion Ball, and Bruce Blum, moderated by Alexa McCray [24]. The second panel covered roughly chronological developments starting in the 1980's covered by Betsy Humphreys and Peter Szolovits; the 1990's discussed by Patricia Brennan and George Hripsack; the first decade of the millennium by Robert Greenes and Siaw-Teng Liaw; and the 2010 decade and the future by Wendy Chapman and Neil Sarkar. Casimir Kulikowski moderated. The panelists covered achievements and persistent challenges faced by the field, such as those related to the very definition of information and problems of knowledge representation. They pointed to the persistence of silos of expertise that have impeded technical and professional progress, which aggravates the perennial problems that clinical organizations have with legacy systems from IT suppliers which are rarely technologically up-to-date, and not easily customizable to specific clinical environments. During the ACMI dinner the day prior to the panels, the ACMI Committee of Historians presented Dr. Lindberg with a commemorative medal on the occasion of his retirement after 30 years as Director of the NLM. The Medal honors his leadership of biomedical and health informatics both nationally and in the international sphere.

\section{History Workshop at Medinfo 2015 in Sao Paulo, Brazil}

The History Workshop involved four major activities with a focus on the History WG itself. First, it reviewed progress on the IMIA 50th Anniversary History Project, discussed how regional efforts contributed to the work while presenting challenges related to overlap of efforts. Second, it identified the unique worldwide aspects for defining the scope of IMIA history to guide the History WG in comparing and contrasting historical themes and topics with current research and challenges in the field. Third, the Workshop sought to receive broader input from Medinfo 2015 participants on the coverage of content and proposed outline of the 50th Anniversary IMIA History volume, while it encouraged attendees to join the History WG. Finally, feedback was sought on software infrastructure and informatics methods for analysis, display/visualization, and retrieval of the history project materials and MediaWiki updates necessary to support the effort. The History WG was surprised and delighted to receive the Working Group of the Year Award presented at the General Assembly Meeting!

\section{History Workshop at EFMI- STC 2016 in Paris, France}

A workshop was organized by Mihalas, Kulikowski, and Séroussi on "European Medical Informatics History: Peoples and Events", which featured an initial major presentation by Isabelle Grémy, who outlined her father's life, and his pioneering work in medical informatics leading to the founding of IFIP TC4. 
Rolf Engelbrecht invoked the memory of another pioneer, Peter Reichertz, who galvanized the German medical informatics field in the 1970's and 1980's, while Mira Hercjgonja-Szekeres outlined the history of medical and nursing informatics in Croatia, with special attention to the educational components. John Mantas discussed the development of curricula in medical informatics, and Casimir Kulikowski gave an update on the $50^{\text {th }}$ Anniversary IMIA History Project, while George Mihalas concluded with comments on different evolutionary trajectories in countries that were in socio-economic and political transition in Eastern Europe.

\section{IMIA History Activities in Nursing Informatics NI-2016, Geneva, Switzerland}

NI-2016 proved to be an excellent venue in which to engage the nursing community in the activities of the IMIA History WG, since nursing informatics started writing its history in the 1980's, long before medical informatics itself. Connections were made and contributions to the IMIA $50^{\text {th }}$ Anniversary History volume were volunteered by nursing informatics specialists from around the world. A panel organized by Luis Luque on the topic "Social Media as catalyzer for Connected Health, hype or hope? Perspectives from IMIA Working Groups" included Luis Fernandez-Luque, Vivian Vilmarlund, Elizabeth Borycki, Stefan Schulz, Craig Kuziemsky, Michael Marschollek, and Casimir Kulikowski. The panel discussed how social media had become an avenue to accessing, creating, and sharing health information among patients and healthcare professionals, becoming a key feature in many eHealth solutions, including wearable technologies, Big Data solutions, eLearning systems, serious games, and medical imaging. Panelists discussed how these hyper-connected technologies are facilitating the creation of a new paradigm shift towards more connected health, and how this is affecting biomedical and health informatics from a historical perspective.

\section{EFMI@ 40 Panel at HEC-MIE 2016 in Munich, Germany}

Besides the workshop on EFMI and IMIA history organized by Mihalas and Kulikowski, a panel "Anticipating the Future while Appreciating the Past" was organized by Anne Moen, the President of EFMI, which covered topics such as the interactions between people, technologies, and information; the role of computer-assisted diagnosis in the genomic era; and how digital health can result from patient engagement. Panelists included Mihalas, who summarized the history and challenges of computer-assisted decision support; Kulikowski, who emphasized the importance of designing technologies that are responsive to patient and practitioner needs, rather than IT and administrative needs; and Hoerbst, who discussed eHealth issues. Moen offered concluding comments on patient apps, consumer strategies, and patient engagement. During the IMIA GA meeting the History WG was even more surprised than at the previous GA to receive the WG of the Year Award for a second year running!

\section{ACMI History Workshop at AMIA 2016, in Chicago, celebrating the $40^{\text {th }}$ Anniversary of the Symposium on Computers in Medical Care (SCAMC)}

The first SCAMC in 1976 held near Washington, DC, began a long and successful series of conferences that helped define and coalesce biomedical and health informatics as a professional field in the US, while also encouraging considerable international participation. In 1988, SCAMC was one of the three organizations that merged to create AMIA. Coverage of the very wide breadth of biomedical informatics disciplines and depth of scientific and clinical involvement has been carried on successfully by AMIA through its meetings to the present day. The panel was moderated by Casimir Kulikowski and included Michael Ackerman, Marion Ball, Robert Greenes, Judy Ozbolt, and Ted Shortliffe giving their historical perspectives on early SCAMCs, and major work on AI in Medicine, Clinical Decision Support, and Nursing Informatics, while Josh Denny, Jacqueline Merrill, and Anne Moen gave Perspectives on recent Biomedical and Health Informatics challenges. This was followed by a lively audience discussion, sharing their experiences on the topic of enduring challenges to the field.

\section{Activities Leading up to the $50^{\text {th }}$ Anniversary History of International Biomedical and Health Informatics}

At this point, with the IMIA History WG formally in place, invitations have been extended to potential contributors to biomedical and health informatics (BMHI) internationally and many short, personal story contributions have been already received about how pioneers and leaders came to be involved in biomedical and health informatics. This main section of the $50^{\text {th }}$ Anniversary IMIA History will illustrate the diversity of motivations, inspirations, and early contributions across the different specialties and threads of research, practice, and education. They are the kinds of stories unlikely to be emphasized in more traditional curricula or professional work descriptions. In this way, they are intended as original contributions that supplement previously published materials on the History of BMHI in the IMIA Yearbook, the journals of the Association, and other sources.

Coordination with other working groups involved in medical, nursing, social, ethical, and scientific aspects of the field has been discussed in order that contributors provide not only their personal statements of how they have contributed to the field of BMHI, but also how the other working and special interest groups have contributed to their respective histories. 
The authors have been delighted by the many stories they have encountered over the seven years summarized in this report. Biomedical and health informatics has clearly attracted an astonishing array of committed scholars and professionals whose focus is to improve human health through the information sciences applied to health and human suffering. The overwhelming interest and support we have found throughout the global community and, indeed, even from family members associated with our past leaders makes us confident that the future history of this discipline will continue to be meaningful and help us to better place into perspective the ongoing challenges faced by our field.

\section{Acknowledgements}

The authors wish to thank and acknowledge the suggestions and help of their colleagues of the IMIA History Working Group and the ACMI Committee of Historians, as well as the reviewers and editors of the IMIA Yearbook of Medical Informatics without which this work would not have been possible.

\section{References}

1. Peterson HE, Lundin P. Documenting the Use of Computers in Swedish Health Care up to 1980. Yearb Med Inform 2011:169-74.

2. Van Bemmel JH. People and Ideas in Medical Informatics - A Half-Century Review. Yearb Med
Inform 2011:175-82.

3. Ball M. Back to the Future: What Have We Failed to Learn? How Does the Future Look? Yearb Med Inform 2011: 196-8.

4. Yacubsohn V.A Short History of the Beginnings of Hospital Information Systems in Argentina, Yearb Med Inform 2012:163-8.

5. Fieschi M. The Development of AI in Medicine and the Research Environment of the SPHINX Project at the Start of the 1980s. Yearb Med Inform 2012:153-60.

6. Ball MJ, van Bemmel JH, Kaihara S. IMIA Presidential Retrospectives on Medical Informatics. Yearb Med Inform 2007:165-75.

7. Lindberg DAB. The Evolution of Medical Informatics. In: Myers JD, editor. Medical Education in the Information Age. Proc SCAMC, Assoc Amer Med Colleges. 1986: 86-95.

8. Blum BI, Duncan K. A History of Medical Informatics. New York: Addison-Wesley. ACM History Series; 1987.

9. Collen MF. A History of Medical Informatics in the United States. Indianapolis, IN: AMIA; 1995.

10. The Nursing Informatics Project http://www.amia. or/programs/working-groups/nursing-informatics/ history-project

11. Ozbolt J, Saba V. A brief history of nursing informatics in the United States of America. Nurs Outlook 2008 Sep-Oct;56(5):199-205.e2.

12. Hasman A, Albert A, Wainwright P, Kar R, Sosa $M$. Education and Training in Health Informatics in Europe. Amsterdam: IOS Press; 1995.

13. Zvárová J. Education in Methodology for Health Care - EuroMISE. Methods Inf Med 1994;33: 315-7.

14. Hasman A, Prokosch HU, Dudeck J, Gell G, Engelbrecht R, editors. Medical Infobahn for Europe. Stud Techn Health Inform 2000;77:1-1274.

15. Mihalas GI. An attempt to define major stages of Medical Informatics development. CD Pro- ceedings IMIA-LAC Conference, Guadalajara, Mexico; 2011.

16. Kulikowski C, McGrew C. An Informatics Approach to Chronicling the History of IMIA. Proc Medinfo 2013:1130.

17. Mihalas G, Zvarova J, Kulikowski C. European History of Medical Informatics. Proc EFMI STC, Prague, 2013. www.stc2013.org/joint-activities/ panels

18. Mihalas GI, Zvarova J, Kulikowski C, Ball M, van Bemmel JH, Hasman A, et al. History of Medical Informatics in Europe - a Short Review by Different Approach. Acta Inform Med 2014;22(1):6-10.

19. Mihalas GI. Evolution of Trends in European Medical Informatics. Acta Inform Med 2014; 22(1):37-43.

20. Kulikowski C. The 50th Anniversary IMIA History of Medical Informatics Project. Acta Inform Med 2014; 22(1):68-70.

21. Deželić G, Kern J, Petrovečki M, Ilakovac V, Hercigonja-Szekeres M. Medical Informatics in Croatia- a Historical Survey. Acta Inform Med 2014;22:49-59

22. Masic I, Mihalas G. Contributions to the History of Medical Informatics, Avicenna, Sarajevo; 2014.

23. Mihalas GI, van Bemmel JH, Richards B, Engelbrecht R, Masic I, Haux R, et al. Medical Informatics History - A View from Socio-Political Context in European Countries. Workshop MIE 2014, Istanbul.

24. McCray A. ACMI at 30 - The Founding of the American College of Medical Informatics and the American Medical Informatics Association. Proc AMIA 2014. Washington, DC; 2014.

\section{Correspondence to:}

Casimir A. Kulikowski

Department of Computer Science

Rutgers - The State University of New Jersey

Piscataway, New Jersey, USA

E-mail: kulikows@cs.rutgers.edu 